\title{
CONSIDERAÇÕES SOBRE O PENSAMENTO JURÍDICO CRÍTICO E A SUSTENTABILIDADE
}

\section{RESUMO}

Nesse ensaio buscamos desenvolver uma reflexão sobre as possíveis contribuições da teoria crítica para o pensamento jurídico e ampliação da compreensão sobre a sustentabilidade. O objetivo proposto é o de discutir a influência da Escola de Frankfurt para o pensamento jurídico, no que se refere à relação entre o homem e a natureza, sugerindo uma perspectiva analítica diferenciada para o operador de direito. Produzindo dessa forma maior profundidade no debate ambiental na atualidade.

Palavras-chave: Teoria Critica. Pensamento Jurídico. Sustentabilidade.

${ }^{1}$ Biólogo formado pela Faculdade de Ciências Agrárias e Veterinárias - FCAV - UNESP Campus de Jaboticabal, Especialista em Educação Ambiental pela UFSCAR. Aluno do Curso de Direito da Faculdade de Direito de Franca (FDF). Consultor em Sustentabilidade, Meio Ambiente e Negócios Jurídicos. Currículo Lattes: http://lattes.cnpq.br/5335923561458883.E-mail: gomesdepaulajr@gmail.com 


\section{INTRODUÇÃO}

A Teoria Crítica ficou assim conhecida como "teoria da sociedade" por analisar questões estruturais da organização da sociedade como, por exemplo, o desemprego, condições das massas, terrorismo, fome, poluição entre outros. A teoria Critica buscando aliar a teoria e a prática se opõe radicalmente ao pensamento tradicional e por consequência cria uma perturbação na compreensão do conhecimento e na racionalidade ambiental.

Através do Instituto de Pesquisas Sociais, a Escola de Frankfurt analisou as relações sociais, na Filosofia, Antropologia, Psicologia, Direito e na Comunicação Social. O ensaio "Teoria Tradicional e Teoria Crítica" de Max Horkheimer (1937) inaugura a Teoria Crítica da Sociedade sendo desenvolvida por diversos pensadores, principalmente pelos pesquisadores da Escola de Frankfurt.

O objetivo do ensaio é opor-se ao que é designado pela expressão "Teoria Tradicional", que remonta ao Discurso do Método, de Descartes (1637), para Horkheimer (1937) a Teoria Tradicional não se preocupa com as origens sociais dos problemas e acaba, portanto, por ser mais abstrata e distante da realidade, isso se justifica em função na neutralidade do pensador que necessita de distanciamento e proteção das tensões para exercer a sua atividade. A Teoria Crítica, por sua vez, defende o desenvolvimento de diversas teorias atentas às desigualdades socioambientais, aos problemas advindos da relação sociedade e natureza, não somente no campo sociológico, filosófico ou jurídico, vincula-se a um pensamento marxista sem renunciar da crítica ao próprio marxismo, não possuindo um "consenso epistemológico", pois não tem a intenção de possuir uma visão única do mundo.

Acredita-se que a teoria crítica possa promover uma sociedade mais autocrítica, em busca de um maior esclarecimento, e uma perspectiva em relação aos conflitos entre sociedade e a natureza.

Dentro dos participantes da Escola de Frankfurt, citamos rapidamente, os que eram ligados à área jurídica. Otto Kircheimer, autor de Political Justice: the use of legal procedure for political ends, de 1961, e Politics, Law, and Social Chance, de 1969. E Franz Neumann, autor de The Rule of Law: political theory and legal system in modern society de 1936. Pouco conhecidos nos Brasil, esses autores tiveram uma atuação 
secundária no grupo, pois não adotavam diretamente as principais teses da Teoria Crítica sendo muitas vezes tolerados por outros membros do grupo.

Se os juristas da escola de frankfurt desempenhavam papéis secundários, qual a importância da referida corrente teórica para o direito? Respondemos que qualquer pensador não necessita ser da área jurídica para desempenhar uma contribuição para o pensamento jurídico, citamos Kant e Hegel como exemplos de grandes pensadores que contribuíram para a formação jurídica de diversas gerações.

Tanto Adorno quanto Horkheimer não são considerados teóricos do Direito, mas suas reflexões suscitam formulações fundamentais para o entendimento entre sociedade e meio ambiente. Esses autores em questão trouxeram a tona, mesmo que indiretamente, uma profunda discussão sobre a sociedade de consumo, o pensamento ambiental e a sociedade.

Influenciado pela Escola de Frankfurt, Coelho (2003) disserta sobre a Teoria Crítica do Direito:

a) O Direito não é sinônimo de lei: trata-se da noção de que o jurista precisa inserir-se na sociedade para entender que o direito não é apenas aquele originado do Estado. O Direito deve ser identificado como bem comum, com a justiça e a igualdade, não devendo ser utilizado como artifício pelas classes dominantes;

b) O Direito não é uno: a monopolização do Direito pelo Estado é questionada pelo pensamento crítico, que considera um ente contraditório indispensável para a reprodução do sistema capitalista e, nesse sentido, seria também um ente alienador.

c) O Direito não é neutro: a neutralidade, entendida como um distanciamento absoluto da questão a ser apreciada, pressupõe um jurista isento não somente das complexidades, da subjetividade pessoal, mas também das influências sociais;

d) O Direito é um instrumento de transformação social: pois deve ter por objetivo a emancipação da sociedade, a partir da noção de que, contraditoriamente, o mesmo Direito que legitima e reproduz a exploração pode ser elemento fundante de uma mudança 
social, deve criar as condições juridicas necessárias para a emancipação do homem;

Percebe-se, portanto, que o Direito, na concepção da Teoria Crítica, é um ente com profunda contradição que, ao mesmo tempo em que serve os interesses do capital, tem em sua estrutura e origem o potencial emancipatório capaz de instaurar as bases juridicas para a sociedade emancipada. Tentemos realizar algumas considerações em sentido oposto ao usual, considerando o pensamento jurídico e a sustentabilidade não em função dos seus resultados, mas sim como um problema a merecer a meditação filosófica - a filosofia como ensinava Hegel, ver o mundo as avessas, tentando dessa maneira elucidá-lo numa nova perspectiva.

\section{SUSTENTABILIDADE: ORIGENS E DESDOBRAMENTOS.}

Uma das primeiras aparições da ideia de sustentabilidade se deu em 1713, através do alemão Hans Carl von Carlowitz. Diante da escassez da madeira na região da saxônia, Carlowitz cunhou o termo nachhaltigkeit $^{2}$, cuja essência era a de que era preciso garantir a continuada e sustentada utilização das florestas, em um volume de exploração que não viesse a ultrapassar o potencial de renovação da mesma. Carlowitz criticava a visão de curto-prazo dos administradores florestais, argumentando que os lucros com o corte da madeira deveriam ser contrapostos ao fato de que os lucros provenientes das gerações futuras de arvores só aconteceriam após um período longo de tempo (FERREIRA, 2005).

Desde sua origem, esse termo está relacionado à ideia de algo que se sustenta, que deve se manter estável ao longo do tempo. A ideia de sustentabilidade tem sido utilizada desde os primórdios da humanidade, sobretudo, na perspectiva de buscar alternativas de produção e consumo que respeitem a estabilidade do meio ambiente. É possível observar que o discurso da sustentabilidade vem sofrendo importantes modificações ao longo da história.

\footnotetext{
${ }^{2}$ Nachhaltigkeit é traduzido por sustentabilidade, considerado como um princípio que orienta os recursos voltados a preservação das características voltadas para a estabilidade e a capacidade de desenvolver a essencialidade e a capacidade de regeneração natural em cada sistema (BREYER, FREIN, 2009).
} 
O termo desenvolvimento sustentável, do ponto de vista politico, foi utilizado para gerar consenso e diminuir conflitos, de um lado, entre os ambientalistas, e do outro, os desenvolvimentistas, baseando-se nos principais debates ambientais da década de 1970. O movimento ambientalista foi fortemente influenciado pelo caráter catastrófico e de denuncia do livro "The Silent Spring" de Rachel Carson.

Carson (1969), ao discutir a utilização demasiada dos pesticidas impulsionou de maneira decisiva as primeiras iniciativas de proteção ambiental nos Estados Unidos, além de influenciar a opinião pública mundial e fomentar o movimento ambientalista da época.

Praticamente no mesmo período surge o "Clube de Roma", uma entidade privada, sem fins lucrativos, tendo como base financeira, contribuições de uma série de empresa multinacionais, para patrocinar estudos sobre o crescimento econômico no mundo. (OLIVEIRA, 2012).

A ideia principal do Clube seria modificar o ritmo de crescimento econômico de uma forma a desacelerar as atividades econômicas na maioria dos países, incluindo a tendência para uma desestimulação relacionada à industrialização, produção de alimentos e principalmente a diminuição do crescimento populacional. Com a exaustão dos recursos naturais, os limites do crescimento do planeta seriam atingidos em cem anos e a humanidade depararia com uma crise sem precedentes. (OLIVEIRA, 2012).

Com a publicação do estudo "Limits to Growth" (1972), o "Clube de Roma" criticou o "mito" do crescimento econômico ilimitado, esse relatório provocou a comunidade internacional, na medida em que levantava o seguinte questionamento: se o desenvolvimento econômico chegar ao seu limite máximo, a pressão sobre todos os recursos naturais seriam de tal ordem (ou o custo de controle de poluição seria tão alto) que o sistema econômico mundial entraria em colapso. (BRÜSEKE, 1996).

No âmbito da politica internacional, nos documentos resultantes da Conferência de Estocolmo de 1972, argumentava-se que os recursos naturais poderão ser substituíveis por outros fatores de produção, como trabalho e capital reprodutível. Por outro lado, defendia-se que ao se levantar um discurso alarmista, notadamente, sem provas materiais, indica na realidade outros interesses, por exemplo, a possibilidade futura de investimento num modelo eco industrial (MOTA et al. 2008).

Em uma perspectiva histórica, podemos dizer que o termo "Desenvolvimento Sustentável” surge em 1979 no Simpósio das Nações Unidas sobre as Inter-Relações entre Recursos, Ambiente e Desenvolvimento, 
em Estocolmo, e se afirma em 1987 quando o presidente da Comissão Mundial para o Meio Ambiente (CMMA) perante Assembleia Geral da Organização das Nações Unidas (ONU) o coloca como um "conceito político" e um "conceito amplo para o progresso econômico e social" (VEIGA, 2005).

Em 1980, quando o IUCN (Internacional Union for The Conservation of Nature and Natural Resoucer), apresenta o relatório "World Conservation Strategy", que a noção do desenvolvimento sustentável ganha destaque com a promoção da ideia de "alcançar o desenvolvimento sustentável pela conservação dos recursos vivos". Entretanto, somente em 1987, por meio do relatório "Brundtland" também conhecido como "Nosso Futuro Comum", no qual o termo foi definido como "desenvolvimento que satisfaz as necessidades do presente sem comprometer a capacidade das futuras gerações satisfazerem suas próprias necessidades" (ONU, 1991). È importante salientar que um marco importante na construção das diferentes ideias sobre sustentabilidade ocorreu em 1983, quando foi criada pela ONU a "Comissão Mundial Sobre Meio Ambiente e Desenvolvimento" (VEIGA, 2005).

O Relatório Brundtland ganha notoriedade passando a ser utilizado nos discursos dos organismos internacionais, políticos, intelectuais e movimentos sociais, entretanto, apresenta defeitos e contradições. Como afirma Nobre (2002), são justamente essas contradições que favorecem a aceitação geral do termo, por conseguir reunir sob si uma gama variada de posicionamentos. O relatório tinha como objetivo propor estratégias de longo prazo, de tal forma que essa ideia estivesse amplamente disseminada e implantada por volta do ano 2000 . O relatório também indicava caminhos para que a preocupação com o meio ambiente se traduzisse em maior cooperação entre países de desenvolvimento econômico e social diferentes.

O relatório, embora influenciado pelas ideias de Sachs, chegou a um resultado qualitativamente diferente, ressaltando uma ênfase econômica e tecnológica e uma tônica conciliadora que tendia a alterar a ênfase política da proposta inicial, anteriormente compromissada com os processos de mudança social e diminuição da desigualdade.

$\mathrm{Na}$ avaliação do Relatório é perceptível a ausência de crítica à sociedade industrial, que somente justifica a necessidade de se pensar em novas formas de desenvolvimento, favorecendo o crescimento tanto em países industrializados como em desenvolvimento, inclusive ligando a superação da pobreza nestes últimos ao crescimento contínuo dos primeiros. 
A premissa básica defendida pelo Relatório Brundtland é a constatação de que o planeta é um só e finito. Além disso, os desafios ambientais são comum a toda humanidade, necessitando de um esforço comum de todos. Independente da responsabilidade de quem causa a degradação, a busca de soluções é uma responsabilidade de todas as gerações. (VEIGA, 2005).

Nas palavras de Layarargues (1997), o relatório, na tentativa de generalizar fatos, omite um contexto histórico e cria o "homem abstrato", cuja consequência significa a retirada do componente ideológico da questão ambiental, que passa a ser considerada com certa dose de ingenuidade e descompromisso, frente à falta de visibilidade do procedimento histórico gerador da crise ambiental.

A temática da sustentabilidade, de acordo com os autores Ferreira e Viola (1997), tornou-se um marco referencial nos debates políticos, acadêmicos e sociais, transformando numa ideia-força de grande poder sobre a ordem social e diretamente um campo de batalha simbólico para o significado desse ideal normativo.

Importante destacar que o conceito de sustentabilidade possui um ressignificado ao longo da história. Em 1972 esse conceito aparece com força no trabalho intitulado "Limites do Crescimento", tendo sido este produzido por cientistas e técnicos do Massachussetts Institute of Technology - MIT, por encomenda do Clube de Roma, momentos antes da Conferência da ONU sobre o Meio Ambiente Humano, realizada em Estocolmo.

Todavia, o termo desenvolvimento sustentável acaba ganhando um grande espaço na mídia e em vários setores da sociedade. Nesse sentido, destaca-se o fato de que a Conferência das Nações Unidas para o Meio Ambiente e o Desenvolvimento (CNUMAD), também conhecida como ECO-92, Rio - Cúpula ou Cimeira da Terra, realizada no Rio de Janeiro em 1992, ter consagrado mundialmente a ideia de desenvolvimento sustentável.

Outros encontros promovidos pela ONU contribuíram para consagrar mundialmente a ideia de desenvolvimento sustentável como, por exemplo, a Cúpula Mundial Sobre Desenvolvimento Sustentável, realizada em 2002 em Johanesburgo (África do Sul). Também conhecida como Rio + 10, essa conferência ocorreu após dez anos da Cúpula da Terra, em 1992. Outro aspecto de interesse nessa discussão se refere ao que alguns autores apontam como a ponte que a ideia de desenvolvimento sustentável 
estabeleceu entre os economistas tradicionais e a chamada nova economia ecológica (DINIZ, 2002).

É precisamente esta premissa que a Comissão Brundtland evita abordar. A lógica discursiva acentua discurso acentua a ideia de erradicação da pobreza como a tônica do desenvolvimento sustentável, e assim, estaríamos diante de apenas um problema: a poluição da pobreza. Ao invés de um teto, é preferível, na ótica da Comissão Brundtland, considerar um piso de consumo material. É marcante que a proposta ilusoriamente almeja, quando muito, um nivelamento por cima, e não intermediário.

Importante salientar ainda que a adesão, em certo ponto acrítico, do conceito de desenvolvimento sustentável, também vem ocorrendo por conta de uma ampla utilização do termo em documentos que são "caros" ao movimento ambientalista e ao campo de pesquisa em direito ambiental. Com base nas discussões e documentos gerados durante a Rio/92 através da criação da Carta da Terra, da agenda 21 e do Tratado de Educação Ambiental para as Sociedades Sustentáveis e Responsabilidade Global ("TEASS") surgem diferentes propostas que aliam o meio ambiente a sustentabilidade (DINIZ, 2002).

A Conferência das Nações Unidas para o Meio Ambiente e o Desenvolvimento (CNUMAD), também conhecida como ECO-92, Rio - Cúpula ou Cimeira da Terra, realizada no Rio de Janeiro em 1992, destacou o conceito de desenvolvimento sustentável, contribuindo no sentido de discutir a crise ambiental como fruto do modelo civilizatório atual.

Realizada em 2002 em Joanesburgo, África do Sul, a Cúpula Mundial Sobre Desenvolvimento Sustentável realizou a terceira conferência mundial promovida pela Organização das Nações Unidas para discutir a sustentabilidade ambiental do planeta. A conferência ficou conhecida como Rio + 10, uma vez transcorrido dez anos após a Cúpula da Terra, em 1992 (DINIZ, 2002).

A Declaração Política, intitulada "O Compromisso de Joanesburgo sobre Desenvolvimento Sustentável”, possui sessenta e nove parágrafos divididos em seis partes. Como o nome indica, trata-se de um documento que estabelece posições políticas, e não metas. Assim, reafirma princípios e acordos adotados na Conferência de Estocolmo (1972) e na Rio92, pede o alívio da dívida externa dos países em desenvolvimento e o aumento da assistência financeira para os países pobres, além de reconhecer que os desequilíbrios e a má distribuição de renda, tanto entre países quanto dentro deles, estão no cerne da insustentabilidade ambiental. O texto 
admite ainda que os objetivos estabelecidos na Rio-92 não foram alcançados e conclama as Nações Unidas a instituir um mecanismo de acompanhamento das decisões tomadas na Cúpula de Joanesburgo (DINIZ, 2002).

O segundo e mais importante documento resultante da Cúpula é o Plano de Implementação, que possui dez capítulos e 148 parágrafos em cerca de 70 páginas. Seu mote é alcançar três objetivos supremos: a erradicação da pobreza, a mudança nos padrões insustentáveis de produção e consumo e a proteção dos recursos naturais. Um dos pontos mais relevantes do documento é o tratamento de temas antigos de uma forma que reflete a evolução no cenário internacional desde 1992.

\section{A INDÚSTRIA CULTURAL E A SUSTENTABILIDADE}

O contexto filosófico que se apresenta é o da Escola de Frankfurt, sobretudo em Theodor Adorno preocupou-se em pensar uma educação emancipada, esclarecedora, capaz de construir uma sociedade consciente, formada por pessoas questionadoras, críticas e comprometidas com as políticas públicas e com bem comum.

A Indústria cultural pode ser definida como o conjunto de meios de comunicação como, o cinema, o rádio, a televisão, os jornais, revistas e a internet, que formam um sistema com capacidade de produzir lucros e por terem fácil e amplo acesso às massas, exercem diferentes tipos de manipulação e controle social, quer dizer, não apenas promove a mercantilização da cultura, como é também legitimada pela demanda desses produtos. Ela é uma forma de totalitarismo que impede a individuação e o acesso à cultura (ADORNO e HORKHEIMER, 1973).

Adorno utiliza a expressão indústria cultural para caracterizar o abuso comercial, proporcionando assim a falsa emancipação através dos bens de consumo, enfatizados pelo consumismo para alcançar o lucro. Assim, a Indústria Cultural deformou a cultura, os conceitos e a educação, e a Educação dificilmente torna-se emancipatória. A cultura não é produzida pelas massas, mas pelo Capital. Esse processo é determinante para aquilo que se pode considerar como "Cultura de Massa" que favorece as vontades e determinações evidenciadas pelo poder do capital, onde a Cultura não é cultura, mas imposição de vontades e determinações do capital para com o ser humano. 
Adorno mostra que a educação é a saída para essa realidade, não a educação deformadora, mas a educação da conscientização, da construção intelectual, comprometida com seu fim e não os fins lucrativos. E torna-se escapatória pelas poucas pessoas conscientes desses fatos que possam assumir uma posição contra a subordinação.

A educação tem um papel fundamental para tornar a sociedade emancipada, terá bons resultados se for aplicada de forma séria, comprometida com o seu fim, capaz de despertar nas pessoas o interesse pelo bem estar verdadeiramente humano.

A Indústria Cultural é uma expressão utilizada por e Horkheimer e Adorno na obra "Dialética do Esclarecimento" (1973) para denominar os elementos característicos do mundo industrial moderno. Nela o homem se converte em mero agente da lei do valor e se transforma em ser passivo determinado pelo poder e pela lógica da circulação das mercadorias e do acúmulo do capital. $\mathrm{Na}$ Indústria Cultural tudo se torna negócio.

No texto "O Iluminismo como mistificação das massas" Adorno (2009, p. 5) afirma que Indústria Cultural é tão bem aceita e inquestionável, que os seus dirigentes não se dão ao trabalho de encobertá-la, determinam as pessoas para o consumo descontrolado:

A unidade evidente do macrocosmo e do microcosmo demonstra para os homens um modelo de sua cultura: a falsa identidade do universal e do particular. Sob o poder do monopólio, toda cultura de massas é idêntica, e seu esqueleto, a ossatura conceitual fabricada por aquele, começa a se delinear. Os dirigentes não estão mais sequer muito interessados em encobri-lo, seu poder se fortalece quanto mais brutalmente ele se confessa de público. O cinema e o rádio não precisam mais se apresentar como arte. A verdade de que não passam de um negócio, eles a utilizam como uma ideologia destinada a legitimar o lixo que proporcionalmente produzem. Eles se definem a si mesmos como indústrias, e as cifras publicadas dos rendimentos de seus direitos gerais suprimem toda dúvida quanto à necessidade social de seus produtos.

Essa cultura, totalmente ligada ao comércio, alimenta a supremacia do capitalismo na sociedade contemporânea. Demonstra que a nova 
sociedade está atrelada diretamente aos bens de consumo, dependente do mercado, do comércio, da negociação.

A indústria cultural causa uma falsa impressão de esclarecimento e de liberdade a sociedade. Causa uma satisfação momentânea, porém incessante, já que o homem precisa consumir para se sentir bem e aceito na sociedade, pois, proporciona necessidades. As necessidades afins a sua exigência, ao consumo incessantemente, com isso, o consumidor será sempre insatisfeito, consumindo constantemente. Nesse sentido, o universo social, configura-se como um universo de coisas.

Para Adorno (1973), a tecnologia mudou os valores das pessoas, inseriu nelas uma direta identificação e intimidade com as coisas. Os objetos, do mundo tecnológico, deixam de ser meros objetos em função da existência do homem e tornam-se objetos de amor, paixão, fetiche. O homem sentimental e afetivo perdeu essas características, tornou-se mecânico, submerso no mundo utilitário e alienado pelo prestígio dado ao dinheiro.

Adorno e Horkeimer (1973, p. 93) em "Dialética do Esclarecimento" explicam que o consumidor sente tanta satisfação ao ponto de ser incapaz de perceber que é vítima de um processo manipulador.

O consumidor não é rei, como a indústria cultural gostaria de fazer crer, ele não é sujeito dessa indústria, mas o seu objeto. O termo mass media, que se introduziu para designar a indústria cultural, desvia, desde logo, a ênfase para aquilo é inofensivo. Não se trata nem das massas em primeiro lugar, nem das técnicas de comunicação como tais, mas do espírito que lhes é insuflado, a saber, a voz de seu senhor. A indústria cultural abusa da consideração das massas para reiterar, firmar e reforçar a mentalidade destas, que ela toma como dada a priori e imutável. É excluído tudo pelo que essa atitude poderia ser transformada. As massas não são a medida, mas a ideologia da indústria cultural, ainda que esta última não possa exigir sem a elas se adaptar.

Os padrões da indústria cultural surgem das necessidades dos consumidores. Tais necessidades estão ligadas ao cotidiano das pessoas, a bens desejáveis como o conforto, a beleza, as facilidades, a satisfação. O mercado produz o "melhor" para cada vontade, ele proporciona a satisfação para cada ansiedade. Por isso é tão bem visto. Esse triunfo se dá porque é 
incutida nas pessoas a falsa impressão de independência, resultante na falsa impressão de satisfação.

A indústria cultural pode ser vista de duas formas, educativa ou deformativa. Na primeira, se analisada do ponto de vista do sistema, é plenamente educativa, pois adequa os homens aos seus interesses, a servidão e dependência para a manipulação. Já na segunda, sendo analisada a partir dos pressupostos da teoria crítica, é terminantemente deformativa. Analisada pela teoria crítica, a Indústria Cultural não tem valores benéficos, só mesmo o capital seria capaz de lhe atribuir algum valor educativo construtivo.

O destino educativo do indivíduo é totalmente dependente da indústria cultural. Por causa da desvalorização da razão, o homem deixa de exercer a reflexão e perde as qualidades que não lhe são mais úteis e que só os atrapalham. Com a vulgarização da cultura, as artes não precisam mais ser pensadas, são banalizadas. Dessa forma o indivíduo para de utilizar a razão, fica propício ao enquadramento e à subordinação de outro (capitalismo). Conseqüentemente, é dominado pelo processo econômico.

A opressão social não é vista, acontece anonimamente, obscurecida. A falta de maturidade das massas é o reflexo do fato de que os homens continuam não sendo senhores autônomos de sua vida, são membros de uma democracia onde a democracia não é exercida, porque nessa cultura não têm condições para exercê-la, são alienados.

A coisificação da consciência pode levar às pessoas a tornaremse indiferentes ao outro, ceder à pressão e ao poder por quaisquer idéias de pouca ou nenhuma credibilidade, não contrapor ao poder cego dos coletivos, continuar a fazer coisas que perpetuam sua própria servidão (ADORNO, 1973).

Controlando a escolha da população e instaurando o poder da técnica sobre o homem, a indústria cultural cria condições favoráveis para a implantação do seu comércio.

Qualquer meio de comunicação pode criar uma ilusão de um mundo que não equivale à realidade, é o que interessa ao sistema econômico e político no qual se insere a indústria cultural. $\mathrm{O}$ homem é subordinado ao progresso da técnica e está o destrói, destruindo sua subjetividade para dar lugar a razão instrumental, ou seja, a razão é reduzida a instrumentalidade.

O que podemos perceber a partir do momento em que a cultura se torna mercadoria é que passamos a viver por uma sociedade conduzida 
não por um projeto político ou ideológico, mas uma sociedade dirigida e orientada pela técnica.

Adorno, afirma que para a indústria cultural o consumidor não é sujeito e sim objeto, assim podemos dizer que os produtos culturais relacionados com a sustentabilidade, 'sacolas ecológicas' ou uma camiseta com os dizeres "salvem as baleias" possuem o mesmo esquema de organização e de planejamento administrativo que a fabricação de ônibus escolares ou fogões elétricos.

No século XXI o avanço tecnologico especialmente na biotecnologia e na tecnologia da informação, as mudanças nas condições gerais de produção industrial possibilitada pela informatização e automação, novos materiais, como a substituição de matérias-primas tradicionais,formação de novos hábitos de consumo, introdução de processos produtivos " poupadores de energia" e " ecologicamente eficientes" e a segmentação do mercados consumidores são oferecidos no sentido de atender as novas demandas do mercado.

Desse modo, em principio, a sustentabilidade surge como opção para melhorar ou diminuir os conflitos gerados entre o capitalismo e a sociedade perante os desequilíbrios causados ao meio ambiente. O que parece estar em jogo quando se trata desse assunto seria o pretexto de modernizar as relações entre sociedade e natureza, que nessa fase do sistema capitalista, é representado pela adoção como diria Leff (2001) de um termo que surge a partir da busca de um conceito capaz de "ecologizar" a economia, eliminando a contradição entre crescimento econômico e a preservação ambiental e que, por consequiência, a sustentabilidade torna-se termo substitutivo ao desenvolvimento econômico.

Segundo Marcuse (1973), as formas de manutenção encontradas para manter o capitalismo tardio, da sociedade industrial da década de 1970, com diferenças plausíveis para os tempos atuais, mas ideologicamente semelhantes, são formas de controles indiretas que se encontram na própria forma de organizar a sociedade, o trabalho, a escola e moldam o pensamento humano para tornar-se unidimensional.

Aos estudantes de direito e operadores de direito que defendem a sustentabilidade como proposta de mudança entre as relações sociedade e natureza, é necessária uma maior compreensão de seus atos, pois suas atividades podem acabar comprometidas política e ideologicamente com os interesses e poderes conservadores, sendo executores de uma prática "verde" que não atende na realidade uma melhoria social. 
Na sociedade tomada pelos meios de comunicação de massa, pela propaganda e pelo consumo que influenciam o pensamento humano de tal forma a torná-lo unidimensional impedindo assim o desenvolvimento da subjetividade autônoma, perdendo o poder e a capacidade para a auto-reflexão.

De acordo com Adorno (1995) são profundamente limitadas as condições para mudar os pressupostos sociais e políticos, as condições objetivas, que produziram acontecimentos iguais a Auschwitz, as tentativas de oposição são direcionadas para o lado subjetivo, no sentido de investir no sujeito, na formação da subjetividade autônoma e por isso é de extrema importância a formação da subjetividade autônoma pela via da educação, pois "a exigência que Auschwitz não se repita é a primeira de todas para a educação" (ADORNO, 1995, p. 119).

O desenvolvimento da comunicação de massa teve uma influência fundamental sobre a natureza da cultura e sobre a ideologia nas sociedades modernas.

Na perspectiva de Adorno, a análise da ideologia não deve se limitar a doutrina política, sim abranger as diferentes formas simbólicas que circulam no mundo social, através das relações existentes no seio da sociedade de maneira a se entender a forma como se produz e se intensificam a massificação do individuo. Assim, a cultura é o instrumento capaz de desenvolver e criar as formas de controle das concepções sociais e das ideologias estruturadas na sociedade capitalista.

As questões ideológicas que fundamentam o discurso da racionalidade ambiental podem ser analisadas em Leff (2001) e se apresentam como um discurso que se caracterizam como um processo que envolve o homem e a sociedade. Na sua visão, a construção de uma racionalidade ambiental surge de um conjunto de processos de "racionalização", com diferentes " instancias de racionalidade" que conferem legitimidade à tomada de decisões com respeito ao dominio da natureza e a eficacia a seus sistemas produtivos (LEFF, 2001).

O desenvolvimento da modernidade foi baseado nos principios da racionalidade econômica e instrumental que influenciou a tecnologia, as práticas produtivas a burocracia. A problematica ecológica questiona os custos socioambientais derivados de uma racionalidade produtiva fundada no calculo econômico, na uniformidade dos comportamentos sociais e na eficiencia de seus meios tecnológicos. 
O conceito de ambiente necessita de novas perspectivas em relação ao desenvolvimento propondo novos principios éticos, e uma nova proposta de pensamento econômico, tecnológico e formativo no ensino do direito, para se chegar a uma nova racionalidade que abarque um conjunto de mudanças sociais para internalizar e transformar as bases ecológicas e sociais que levarão a real sustentabilidade.

As contradições entre as racionalidades ecológicas e a racionalidade jurídica se dão atraves de um confronto de diferentes valores infiltrados nas instituições e em paradigmas de conhecimento. A racionalidade jurídica sempre se associou a uma racionalidade de cunho cientifico e tecnológico com a intenção de aumentar o grau de certeza, previsão e confiabilidade. (LEFF, 2008). A Racionalidade Ambiental questiona em definitivo a racionalidade cientifica como mero instrumento de dominação de todas as ordens sociais. Dessa maneira Marcuse nos adverte: "No desenvolvimento da racionalidade, a irracionalidade se converte em razão: razão como desenvolvimento frenético da produtividade, como conquista da natureza $[. .$.$] o dominio da natureza e a riqueza social se convertem em forças$ destrutivas" (MARCUSE,1968/1972).

\section{CONCLUSÕES}

A constatação de que a indústria cultural lança os seus braços à prática educativa, tende a reforçar, mais uma vez, a necessidade de estudantes de direito críticos e pesquisadores capacitados a discernir as transformações dos sujeitos em objetos, e das propostas consideradas sustentáveis transformadas em mercadoria.

Essa mudança pode ser observada inicialmente pelo fato de a indústria cultural abarcar, também, a prática educativa, e, com isso, a transmissão de modo acrítico do princípio do individualismo na valorização da busca do prazer imediato, do sucesso e da felicidade, em substituição aos questionamentos sobre a ordem social, a justiça ambiental e problemática do conhecimento. Em tempos nos quais a sustentabilidade se converteu em um negócio da indústria em pleno processo de expansão, nessa fase de reestruturação das relações de produção, parece um grande desafio romper com o pensamento único e o consenso estabelecido a priori com a disciplinarização homogênea ditada pelo mercado. Isso porque, cabe lembrar, essa tendência a 'conferir a tudo um ar de semelhança' esconde, de fato, 
diferenças e desigualdades social e historicamente construídas, fazendo parecer semelhantes sociedades, classes e frações de classe muito distintas. A sustentabilidade por mais bem-intencionada e teoricamente interessante tem sido apropriada por diferentes esferas da sociedade, em especial o segmento empresarial, e os operadores do direito que fazem um domínio e uma apropriação mercadológica do conceito e limita sua atuação as questões de fácil absorção pela sociedade, tornando-se claramente um produto com data de fabricação e prazo de validade. Na história concreta dos sujeitos, mais do que nunca cabe à pesquisa cientifica desvelar e difundir programaticamente as resistências expressas de distintas formas, que no momento oferecem alternativas ao establishment decorrente da indústria cultural. Para tanto, os operadores do direito devem estar capacitados para lançar mão - inclusive - dos próprios recursos da indústria cultural para possibilitar que as novas gerações venham a recriar as relações entre sociedade e meio ambiente. Utilizando de uma racionalidade que abra novas perspectivas ao processo de desenvolvimento com ênfase na ética, participação social, equidade e justiça ambiental.

\section{REFERÊNCIAS}

ADORNO, T. W. Educação e Emancipação. São Paulo: Editora Paz e Terra, 1995. ADORNO, T.W., HORKHEIMER, M. A indústria cultural: o esclarecimento como mistificação das massas. In: Dialética do esclarecimento: fragmentos filosóficos. Rio de Janeiro, Jorge Zahar Ed, 2006.

ADORNO, Theodor W. Indústria cultural e sociedade. In: COSTA LIMA, Luiz (Org). Teoria da Cultura de Massa. trad. de Júlia Elisabeth. 5. ed., São Paulo: Paz e terra, 2009.

BREYER, Katja, FREIN Michael. Por que uma "Alemanha sustentável'“? Broot fur die Welt, Eeed, 2009.

BRUSEKE, Franz Josef. A economia da sustentabilidade: Princípios desenvolvimento e natureza: Estudos para uma sociedade sustentável. In: CAVALCANTI, Clóvis (Org.) desenvolvimento e natureza: estudos para uma sociedade sustentável. INPSO/FUNDAJ, Instituto de Pesquisas Sociais, Fundação Joaquim Nabuco, Ministério de Educação, Governo Federal, Recife, Brasil. Outubro 1994. p. 262.

CARSON, Rachel. Primavera Silenciosa. São Paulo: Melhoramentos, 1969.

COELHO, Luiz Fernando. Teoria crítica do direito. 2.ed. Porto Alegre: Sergio Antonio Fabris Editor, 1991. 
DINIZ, Eliezer Martins. Os Resultados da Rio +10 . Revista do Departamento de Geografia, 15 (2002) 31-35.

DOBSON, A. (1996) Environmental sustainabilities: an analysis and a tipology, a: Environmental Politics 5(3), pp. 401-428

FEREIRA, Leila da C. e VIOLA, E. (orgs.) Incertezas de Sustentabilidade na Globalização. Campinas: editora da Unicamp,1997.

FERREIRA, L. C. Ideias para uma sociologia da questão ambiental no Brasil. São Paulo: AnnaBlume, 2006.

LAYRARGUES, P. P. Do ecodesenvolvimento ao desenvolvimento sustentável: evolução de um conceito? Revista Proposta, v. 25, n. 71, p. 5-10, 1997.

LEFF, E. Epistemologia ambiental. São Paulo: Cortez, 2001.

Saber ambiental: sustentabilidade, racionalidade, complexidade. Petrópolis, RJ: Vozes, 2008.

MARCUSE, H. A ideologia da sociedade industrial: o homem unidimensional. Tradução Gianone Rebuá. Rio de Janeiro: Zahar Editores, 1973. $4^{\mathrm{a}}$ ed.

MOTA, Jose Aroudo et al. Trajetória da governança ambiental. IPEA, Regional e urbano, dez. 2008.

SACHS, W. (2003) Environment and Human Rights, Wuppertal Papers, N. 137, Novembre, Wuppertal Institute for Climate, Environment, Energy, Wuppertal, $40 \mathrm{pp}$.

VEIGA,E. J. A. Desenvolvimento sustentável: o desafio do século XXI. São Paulo: Garamond, 2005.

WCED (1987), Our Common future, Oxford University Press.

WOLKMER, Antônio Carlos. Pluralismo Jurídico: fundamentos de uma nova cultura do Direito. 3. ed. São Paulo: Alfa-ômega, 2001. 